\title{
Ultra-early angiographic vasospasm associated with delayed cerebral ischemia and infarction following aneurysmal subarachnoid hemorrhage
}

\author{
Fawaz AI-Mufti, MD, ${ }^{1}$ David Roh, MD, ${ }^{1}$ Shouri Lahiri, MD, ${ }^{1}$ Emma Meyers, BA, ${ }^{1}$ Jens Witsch, MD, \\ Hans-Peter Frey, PhD, ${ }^{1}$ Neha Dangayach, MD, ${ }^{3}$ Cristina Falo, PhD, ${ }^{1}$ Stephan A. Mayer, MD, ${ }^{3}$ \\ Sachin Agarwal, MD,,2 Soojin Park, MD,, ${ }^{1,2}$ Philip M. Meyers, MD, ${ }^{1,2}$ E. Sander Connolly, MD, ${ }^{2}$ \\ Jan Claassen, MD, PhD, ${ }^{1,2}$ and J. Michael Schmidt, PhD, MSc ${ }^{1}$ \\ 'Departments of Neurology and ${ }^{2}$ Neurosurgery, Columbia University Medical Center; and ${ }^{3}$ Departments of Neurology and \\ Neurosurgery, Icahn School of Medicine at Mount Sinai, New York, New York
}

OBJECTIVE The clinical significance of cerebral ultra-early angiographic vasospasm (UEAV), defined as cerebral arterial narrowing within the first 48 hours of aneurysmal subarachnoid hemorrhage (aSAH), remains poorly characterized. The authors sought to determine its frequency, predictors, and impact on functional outcome.

METHODS The authors prospectively studied UEAV in a cohort of 1286 consecutively admitted patients with aSAH between August 1996 and June 2013. Admission clinical, radiographic, and acute clinical course information was documented during patient hospitalization. Functional outcome was assessed at 3 months using the modified Rankin Scale. Logistic regression and Cox proportional hazards models were generated to assess predictors of UEAV and its relationship to delayed cerebral ischemia $(\mathrm{DCl})$ and outcome. Multiple imputation methods were used to address data lost to follow-up.

RESULTS The cohort incidence rate of UEAV was $4.6 \%$. Multivariable logistic regression analysis revealed that younger age, sentinel bleed, and poor admission clinical grade were significantly associated with UEAV. Patients with UEAV had a 2-fold increased risk of DCl (odds ratio [OR] 2.3, 95\% confidence interval [Cl] 1.4-3.9, $p=0.002$ ) and cerebral infarction (OR 2.0, 95\% Cl 1.0-3.9, $p=0.04$ ), after adjusting for known predictors. Excluding patients who experienced sentinel bleeding did not change this effect. Patients with UEAV also had a significantly higher hazard for DCI in a multivariable model. UEAV was not found to be significantly associated with poor functional outcome $(\mathrm{OR} 0.8,95 \% \mathrm{Cl}$ $0.4-1.6, p=0.5)$.

CONCLUSIONS UEAV may be less frequent than has been reported previously. Patients who exhibit UEAV are at higher risk for refractory $\mathrm{DCl}$ that results in cerebral infarction. These patients may benefit from earlier monitoring for signs of $\mathrm{DCl}$ and more aggressive treatment. Further study is needed to determine the long-term functional significance of UEAV. https://thejns.org/doi/abs/10.3171/2016.2.JNS151939

KEY WORDS cerebral vasospasm; subarachnoid hemorrhage; delayed cerebral ischemia; cerebral infarction; functional recovery; vascular disorders

$\mathrm{A}$ NEURYSMAL subarachnoid hemorrhage (aSAH) continues to be associated with high morbidity and mortality despite advances in neurocritical care. ${ }^{33}$ The natural history of aSAH suggests an overall mortality rate of approximately $50 \%,{ }^{14}$ with $10 \%$ of patients dying prior to reaching the hospital, $25 \%$ dying within 24 hours of aSAH onset, and $45 \%$ dying within 30 days. ${ }^{3}$ The most important prognostic determinants for aSAH outcome are neurological grade on initial examination, volume of subarachnoid blood on initial CT, age, preexisting hyperten-

ABBREVIATIONS ACA = anterior cerebral artery; $\mathrm{APACHE}-\mathrm{II}=$ Acute Physiology and Chronic Health Evaluation-II; $\mathrm{Cl}=$ confidence interval; $\mathrm{CTA}=\mathrm{CT}$ angiography; $\mathrm{DCl}$ = delayed cerebral ischemia; DSA = digital subtraction angiography; HR = hazard ratio; ICA = internal carotid artery; MAP = mean arterial pressure; MCA = middle cerebral artery; $\mathrm{mRS}=$ modified Rankin Scale; OR = odd ratio; PCOA = posterior communicating artery; SAH = subarachnoid hemorrhage; UEAV = ultra-early angiographic vasospasm. 
sion, rebleeding, and cerebral infarction from delayed cerebral vasospasm. ${ }^{12,15,19,27}$ Typically, delayed cerebral vasospasm after aSAH begins 3 days after ictus and peaks after 7-8 days. Radiographic vasospasm is noted in 30\%-70\% of angiograms performed at Day 7 after aSAH. Twenty percent to $30 \%$ of patients develop clinical or symptomatic vasospasm, which heralds a poorer prognosis. ${ }^{11,18,34}$

The frequency and clinical significance of ultra-early angiographic vasospasm (UEAV) is not well described. UEAV is defined as cerebral arterial narrowing within the first 48 hours of aneurysmal rupture. ${ }^{2,28}$ Two retrospective analyses of data obtained from the Tirilazad Mesylate in SAH clinical trial studies conducted between 1990 and 1997 have investigated the importance of UEAV.,28 These studies found that UEAV was associated with poor functional outcome, but the characterization of UEAV was limited by the trial design and data available. In the current study we sought to assess the clinical significance of UEAV by determining its frequency, association to delayed cerebral ischemia (DCI), and impact on functional outcome.

\section{Methods \\ Study Population}

We prospectively enrolled 1286 consecutive patients with aSAH admitted to the Neurological Intensive Care Unit of Columbia University Medical Center between August 1996 and June 2013 in the Columbia University SAH Outcomes Project. The study was approved by the institutional review board of Columbia University Medical Center; in all cases written informed consent was obtained from the patient or a surrogate. Patients with SAH adjudicated to be secondary to perimesencephalic bleeds, or SAH related to trauma, rupture of an AVM, or other causes, and age $<18$ years old were not enrolled in the study.

\section{Clinical Management}

Clinical management conformed to Neurocritical Care Society and American Heart Association guidelines. ${ }^{6,9}$ All patients underwent electrocardiograms on admission. Cardiac troponin I testing was performed on admission and thereafter when clinically indicated. All patients received oral nimodipine and intravenous hydration with $0.9 \%$ saline and supplemental fluids as needed to maintain euvolemia. Hypertensive hypervolemic therapy was initiated for symptomatic vasospasm or when severe angiographic vasospasm was diagnosed in poor-grade patients by increasing systolic blood pressure to $180-220 \mathrm{~mm} \mathrm{Hg} .{ }^{21}$

\section{Data Collection}

Demographics, medical history, baseline clinical status, imaging results, as well as treatment and complications during hospitalization were recorded prospectively. Patients and/or their families were contacted at 3 months to conduct a follow-up interview to document their current level of functioning. All data are adjudicated in a weekly meeting with the clinical providers, which requires a consensus agreement of each data point.

\section{Clinical and Radiological Variables}

The diagnosis of aSAH was established by admission CT or by the presence of xanthochromia if the initial CT scan was nondiagnostic. All patients received CT angiography (CTA) and/or digital subtraction angiography (DSA) to determine the presence, size, and location of a ruptured aneurysm. UEAV was determined prospectively and defined as luminal narrowing of the intracranial arteries that was not attributable to intrinsic disease (e.g., arteriosclerosis) and was identified on angiography within 48 hours of ictus. ${ }^{2,28}$ The severity of UEAV cerebral vasospasm was determined retrospectively by neuroradiologists and/or neurointerventionalists for all patients enrolled after 2005 who had DSA available on the hospital Picture Archiving and Communications System. The presence and degree of vasospasm was made in comparison with the normal-caliber proximal vessel and/or the normal contralateral vessel. Mild cerebral vasospasm was defined as $<30 \%$ luminal narrowing, moderate cerebral vasospasm as between $30 \%$ and $50 \%$ luminal narrowing, and severe cerebral vasospasm as $>50 \%$ luminal narrowing. ${ }^{17}$

Sentinel headaches (bleeds) were defined as a sudden, severe headache of previously unfamiliar character and intensity lasting at least 1 hour in the last 4 weeks of ictus. ${ }^{2,28}$ To qualify as a sentinel headache it must be adjudicated that the patient either improved before the ictus bleed or experienced later deterioration that led to a diagnosis of aSAH. ${ }^{13,16}$ Neuroradiological grade was classified by the modified Fisher grade, which included grading of the amount of subarachnoid blood on the initial CT scan as none, diffuse or localized thin, diffuse or localized thick, as well as presence of intraventricular or intracerebral hemorrhage, and hydrocephalus. ${ }^{5}$ DCI from cerebral vasospasm was defined as 1) clinical deterioration, i.e., a new focal deficit, decrease in level of consciousness, or both; and/or 2) a new infarct on CT that was not visible on the admission or immediate postoperative scan, when the cause was believed by the research team to be vasospasm. ${ }^{5}$

\section{Outcome Assessment}

Global outcome was assessed by in-person interview or telephone structured interview at 3 months using the 7-point version of the modified Rankin Scale (mRS) rated from death to symptom-free full recovery $(0){ }^{8}{ }^{825}$ Poor outcome was defined as death or moderate-to-severe disability (unable to walk or tend to bodily needs, mRS score $4-6) .6,7,26$

\section{Statistical Analysis}

Data analyses were performed with R statistical software ( $\mathrm{R}$ version 2.12.2, $\mathrm{R}$ Project). All $\mathrm{p}$ values $\leq 0.05$ were considered significant. Logistic regression was used to identify admission predictors of UEAV and to determine differences between patients with and without UEAV. Cox proportional hazards were calculated to determine if the presence of UEAV affected the rate of DCI. Multivariable models were generated using candidate variables with univariate associations of $p<0.25$. Tests for interactions were performed for all significant variables retained in baseline multivariable models. In accordance 
with Patient-Centered Outcomes Research Institute methodological guidelines ${ }^{23}$ we performed multiple imputation using Bayesian methods ${ }^{30}$ to account for 3-month mRS scores lost to follow-up. Procedures to create and analyze 10 imputed data sets were performed using the "mi" package $^{31}$ for R. Diagnostic plots were used to evaluate the fit of the imputed values produced by the marginal model.

\section{Results}

\section{Frequency and Predictors of UEAV}

In this cohort of patients with aSAH we found that UEAV occurred in approximately 4.6\% (59/1286) of patients. The median day that patients underwent DSA was SAH Day 1 (25\% Day 1, 75\% Day 2), and studies were available in $89 \%(1140 / 1286)$ of patients. UEAV was confirmed using CTA in 15\% (9/59) and DSA in 85\% (50/59). Location data were available for 55 patients; 45 patients experienced vasospasm in a single-vessel territory while 10 patients had vasospasm in multiple-vessel territories. UEAV was present in the anterior circulation in $75.9 \%$ of patients $(\mathrm{n}=44)$ and the posterior circulation in $24.1 \%$ $(\mathrm{n}=14$; Table 1). Patient demographics and clinical characteristics were not significantly different across groups. In a multivariate logistic regression model, younger age, sentinel bleed, and poor Hunt and Hess grade were significantly associated with UEAV (Table 2).

\section{UEAV and Incidence of DCI}

Delayed cerebral vasospasm developed in $23 \%$ of the cohort. UEAV was associated with a 2 -fold increased incidence of developing DCI (odds ratio [OR] 2.3, 95\% confidence interval $[\mathrm{CI}] 1.4-3.9, \mathrm{p}=0.002$ ). This relationship existed whether evaluating symptomatic vasospasm (OR $1.9,95 \%$ CI $1.1-3.3, \mathrm{p}=0.02$ ) or cerebral infarction adjudicated due to cerebral vasospasm (OR 2.0, 95\% CI 1.0-3.9, $\mathrm{p}=0.04)$, and remained highly significant in a multivariable logistic regression model (Table 3; Figs. 1 and 2). An identical multivariable model was constructed excluding patients who experienced sentinel bleeding to determine whether this could confound the interpretation of the re-

TABLE 1. Anatomical distribution of UEAV*

\begin{tabular}{cc}
\hline Location & $\%$ (No.) \\
\hline Anterior circulation & $75.8(44)$ \\
\hline ICA & 10 \\
\hline ACA & 15 \\
\hline MCA & 16 \\
\hline PCoA & 3 \\
\hline Posterior circulation & $24.2(14)$ \\
\hline BA & 4 \\
\hline PCA & 7 \\
\hline VA (intradural) & 3 \\
\hline
\end{tabular}

$\mathrm{BA}=$ basilar artery; $\mathrm{PCA}=$ posterior cerebellar artery; $\mathrm{VA}=$ vertebral artery.

* Location data were available for 55 patients; 45 patients experienced vasospasm in a single-vessel territory while 10 patients had vasospasm in multiple-vessel territories. lationship between UEAV and DCI. We found that this relationship remained significant and relatively unchanged (OR 2.1, 95\% CI 1.1-4.2, $\mathrm{p}=0.026$ ). Imaging to grade UEAV severity was available in $44 \%$ of cases. We found that 11 cases had mild, 10 had moderate, and 5 had severe UEAV. In multivariable models excluding cases without data for UEAV severity, we found a significant association between any UEAV and DCI $(p=0.009)$ but not for UEAV severity and DCI $(\mathrm{p}=0.67)$. In patients who had DCI, UEAV was not associated with an increased risk of cerebral infarction $(p=0.88)$ or with having more vessel territories with cerebral vasospasm $(\mathrm{p}=0.6)$.

\section{UEAV and Timing of Delayed Cerebral Ischemia}

The mean $( \pm$ SD) time to develop DCI was $5.6 \pm 2.9$ days in patients with UEAV compared with $6.8 \pm 3.7$ days without. No patient with UEAV developed DCI after SAH postbleed Day 14. A multivariable Cox proportional hazards model revealed that UEAV was associated with a significantly increased hazard for DCI (Fig. 3). To assess whether this effect might be secondary to the occurrence of sentinel hemorrhages, an identical analysis excluding all patients who experienced sentinel bleeding was conducted and continued to show a 2-fold increased risk of DCI for patients experiencing UEAV.

\section{UEAV and Functional Outcome}

We imputed 3-month mRS scores for $18 \%$ of patients who were lost to follow-up. After controlling for known predictors of aSAH poor outcome including age, admission clinical grade, Acute Physiology and Chronic Health Evaluation-II (APACHE-II) physiological subscore, and aneurysm size $>10 \mathrm{~mm}$, we found that patients with UEAV were not significantly associated with poor functional outcome (OR $0.8,95 \%$ CI $0.4-1.6, p=0.5$ ). No relationship to outcome was found regardless of comparing patients with UEAV to all other patients with aSAH or limiting the analysis to only those patients experiencing DCI. We did not find a significant association of UEAV with functional outcome when excluding patients lost-tofollow-up ( $\mathrm{p}=0.6$, OR 0.83 , 95\% CI 0.41-1.7) instead of imputing their outcomes, or by inserting a bad outcome to replace all missing data from lost-to-follow-up $(\mathrm{p}=0.21$; OR $0.69,95 \%$ CI $0.39-1.2$ ).

\section{Discussion}

In this study of 1286 patients with aSAH we found that 59 patients (4.6\%) experienced UEAV. Younger age, poor clinical grade on admission, and history of sentinel bleeding were associated with the occurrence of UEAV. UEAV was associated with 2-fold increased likelihood of developing DCI. Patients with UEAV also experienced DCI at a faster rate during their hospital course. In contrast to prior studies, UEAV was not found to be associated with poor functional outcome.

Multiple theories have been proposed to explain the etiology of UEAV. Case series describing UEAV report it occurred due to direct manipulation of cerebral vasculature during aneurysm surgery and during angiography following vessel perforation or re-rupturing of a cerebral 
TABLE 2. Admission predictors of UEAV

\begin{tabular}{|c|c|c|c|c|c|c|}
\hline \multirow[b]{2}{*}{ Variable } & \multicolumn{4}{|c|}{ Unadjusted } & \multicolumn{2}{|c|}{ Adjusted } \\
\hline & UEAV (\%) & No UEAV (\%) & OR $(5 \%, 95 \%)$ & $p$ Value & OR $(5 \%, 95 \%)$ & $p$ Value \\
\hline \multicolumn{7}{|l|}{ Demographics } \\
\hline No. of patients & 59 & 1227 & & & & \\
\hline Age $>53$ yrs & $22(37)$ & $675(55)$ & $0.5(0.3,0.8)$ & 0.006 & $0.43(0.25,0.76)$ & 0.003 \\
\hline Females & $44(73)$ & $870(71)$ & $1.1(0.6,2)$ & 0.71 & & \\
\hline Non-Caucasian ethnicity* & $32(53)$ & $685(56)$ & $0.9(0.5,1.5)$ & 0.69 & & \\
\hline Hypertension & $27(46)$ & $585(49)$ & $0.9(0.5,1.5)$ & 0.59 & & \\
\hline Currently smoking & $31(52)$ & $489(40)$ & $1.69(0.9,2.6)$ & 0.09 & & \\
\hline \multicolumn{7}{|l|}{ Admission predictors } \\
\hline Hunt \& Hess Grade $\geq 3$ & $29(48)$ & $357(29)$ & $2.3(1.3,3.8)$ & 0.002 & $2.5(1.4,4.2)$ & $<0.001$ \\
\hline GCS score <8 & $15(25)$ & $256(21)$ & $1.3(0.7,2.3)$ & 0.44 & & \\
\hline Sentinel headache (bleed) & $21(35)$ & $242(20)$ & $2.2(1.3,3.8)$ & 0.005 & $2.0(1.1,3.5)$ & 0.015 \\
\hline Ictal loss of consciousness & $31(52)$ & $490(41)$ & $1.6(0.9,2.6)$ & 0.1 & & \\
\hline APACHE-II physiological score & $7.5(4-9) \dagger$ & $6(4-8) \dagger$ & $1.1(1,1.1)$ & 0.07 & & \\
\hline MAP >112 mm Hg & $33(56)$ & $547(45)$ & $1.5(0.9,2.5)$ & 0.15 & & \\
\hline \multicolumn{7}{|l|}{ Admission CT Scan } \\
\hline Thick SAH $\ddagger$ & $32(53)$ & $583(48)$ & $1.3(0.7,2.1)$ & 0.39 & & \\
\hline Global cerebral edema & $11(18)$ & $230(19)$ & $1(0.5,1.9)$ & 0.93 & & \\
\hline Intraventricular hemorrhage & $32(56)$ & $646(55)$ & $1.1(0.6,1.8)$ & 0.84 & & \\
\hline Intraparenchymal hemorrhage & $19(34)$ & $211(18)$ & $2.3(1.3,4.2)$ & 0.003 & & \\
\hline \multicolumn{7}{|l|}{ Aneurysm characteristics } \\
\hline Anterior location & $22(37)$ & $389(32)$ & $1.55(0.9,2.7)$ & 0.49 & & \\
\hline Aneurysm size $>10 \mathrm{~mm}$ & $15(25)$ & $294(24)$ & $1.1(0.6,1.9)$ & 0.86 & & \\
\hline Clip repair procedure & $39(65)$ & $808(66)$ & $1(0.6,1.6)$ & 0.87 & & \\
\hline $\begin{array}{l}\text { GCS }=\text { Glasgow Coma Scale } \\
\text { * Caucasian ( } 44 \%) \text {, Hispanic ( } 30 \%) \text {, Afr } \\
\dagger \text { Values given as median }(25 \%-75 \%) \text {. } \\
\ddagger \text { Fisher Grade } 3 \text { or modified Fisher Gra }\end{array}$ & Imerica & and Asian & & & & \\
\hline
\end{tabular}

aneurysm. ${ }^{10,20,24,35}$ It has been suggested that mechanical pressure on vessels through the distention of arteries around intracerebral hematomas, raised intracranial pressure, subarachnoid clots, or distended ruptured aneurysms may contribute to vessel narrowing on diagnostic imaging. ${ }^{2}$ UEAV has also been described following rupture of arteriovenous malformations and eclampsia. . $22,29,32^{2}$

Two published studies utilizing the Tirilazad data set ${ }^{2,28}$ have attempted to more fully characterize the phenomenon of UEAV. These studies report an incidence rate of UEAV between $10 \%$ and $13 \%,{ }^{9}$ in contrast to $4.6 \%$ found

\section{TABLE 3. Multivariable relationship of UEAV to DCI}

\begin{tabular}{lcc}
\hline \multicolumn{1}{c}{ Predictors } & OR $(95 \% \mathrm{Cl})$ & $\mathrm{p}$ Value \\
\hline Age $>53$ yrs old & $0.8(0.1-0.2)$ & 0.05 \\
\hline Hunt \& Hess Grade $\geq 3$ & $1.6(1.2-2.2)$ & $<0.001$ \\
\hline Thick SAH* & $1.5(1.1-2.0)$ & $<0.001$ \\
\hline Anterior aneurysm location & $1.3(1.0-1.8)$ & 0.04 \\
\hline MAP $>112$ mm Hg & $1.4(1.1-1.9)$ & 0.01 \\
\hline UEAV & $1.9(1.1-3.3)$ & 0.02 \\
\hline
\end{tabular}

\footnotetext{
* Fisher Grade 3 or modified Fisher Grade 3-4.
}

in the current study. It is unclear what methods were used to detect UEAV in these studies. The presence of UEAV was determined in the current study using DSA in $85 \%$ of cases, making it unlikely that the differences in incidence are due to our underdetection of UEAV. The difference in incidence may be attributable to the higher proportion of women enrolled in the Tirilazad studies (81\%) compared with the current study $(71 \%)$ as it has been shown that women are more at risk for cerebral vasospasm. ${ }^{4}$ The 5 Tirilazad studies were conducted in Europe, Australia, New Zealand, South Africa, and North America. Regional differences in diet and smoking may also contribute to the increased incidence of UEAV. The current study enrolled a diverse population composed of Caucasian (44\%), Hispanic (30\%), African American (17\%), and Asian (5\%) patients, and it is unknown to what extent that genetic factors due to race may play a role in the development of UEAV.

It was found in the Tirilazad data $\operatorname{set}^{2,28}$ that poor clinical grade, history of hypertension, and history of previous subarachnoid hemorrhage were predictors of UEAV. We found that UEAV was twice as common in patients with poor clinical grade and those having the presence of intracranial hemorrhage on admission CT scans. Our data also showed that the presence of sentinel headaches pre- 

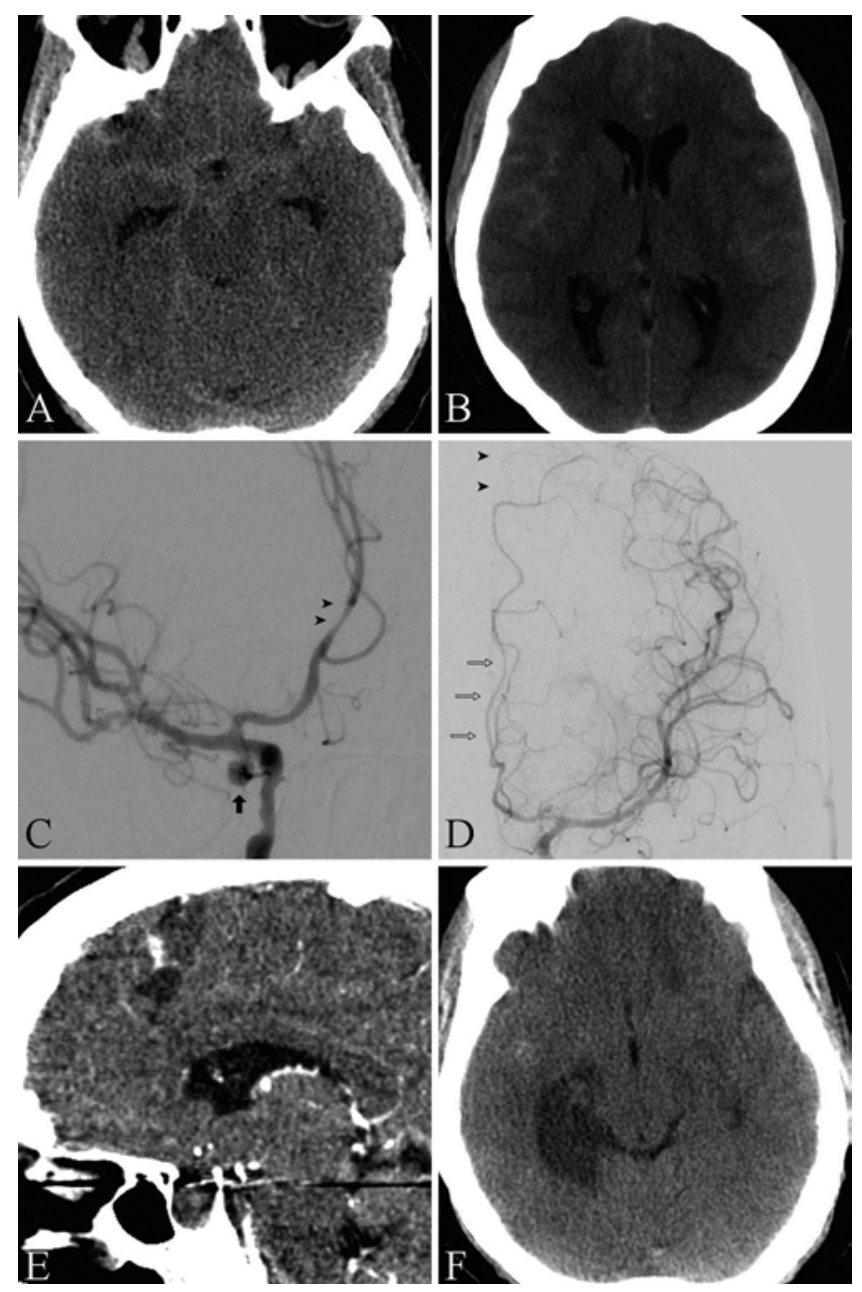

FIG. 1. A and B: Noncontrast axial head CT scans showing diffuse $\mathrm{SAH}$ in the suprasellar cistern and minimal intraventricular hemorrhage. C: Right internal carotid artery (ICA) angiogram showing ruptured right posterior communicating artery $(\mathrm{PCOA})$ aneurysm (arrow) and early vasospasm of the $\mathrm{A}_{2}$ segment of the right anterior cerebral artery (ACA; arrowheads). D: Left ICA angiogram showing early vasospasm of pericallosal and callosomarginal branches of the left ACA. Note the scarcity and delayed opacification of distal ACA cortical branches (arrows) compared with the left middle cerebral artery (MCA; arrowheads). E and F: Sagittal and axial head CT scans on Day 6 showing new infarcts in the posterior left frontal lobe and inferior right temporal lobe.

dicted a 2-fold increased incidence of developing UEAV. In a prospective study of 422 patients, the incidence of sentinel headaches was $20 \%$, which is consistent with the incidence that we found in our cohort. ${ }^{16}$ The occurrence of sentinel headaches was not collected during the Tirilazad studies; thus Qureshi et al. ${ }^{28}$ and Baldwin et al. ${ }^{2}$ could not evaluate the role of sentinel headaches on the occurrence of UEAV. The association between UEAV and sentinel headaches suggests that the etiology of the UEAV phenomena may be in response to exposure to breakdown products of blood clots during previous episodes of subclinical bleeding into the subarachnoid space. If true, the timing of vasospasm relative to the first introduction of blood to the subarachnoid space would be consistent with the timing of delayed cerebral vasospasm and DCI. UEAV
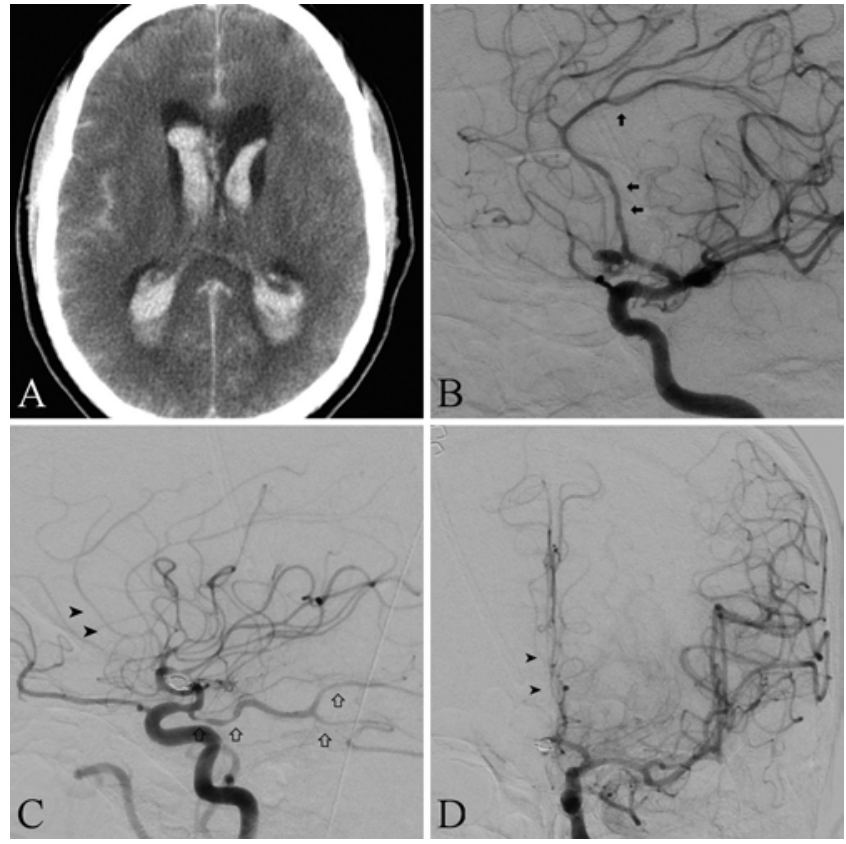

FIG. 2. A: Axial noncontrast head CT scan showing diffuse SAH and massive intraventricular hemorrhage. B: Left ICA angiogram, oblique view, showing a ruptured anterior communicating artery aneurysm and early vasospasm of the $A_{2}$ and $A_{3}$ segments (arrows). C: Postcoiling angiogram on Day 10 of the right ICA, lateral view, showing an embolized aneurysm and new vasospasm of the right PCoA (open arrows). D: Left ICA angiogram, frontal view, showing persistent spasm of right ACA vessels (arrowheads in $C$ and $D$ ).

was a significant predictor of the development of symptomatic vasospasm and preceded the development of DCI in a multivariable model. However, we did not find support for the hypothesis that sentinel bleeding drove this relationship. Even after excluding patients who experienced sentinel bleeding from the multivariable analysis, UEAV was still associated with a 2-fold increased risk for DCI. These findings suggest that the presence of UEAV has clinical significance regarding the onset of DCI and the occurrence of cerebral infarction. Clinicians should be vigilant and monitor these patients for signs of symptomatic vasospasm as early as SAH Day 2 and recognize these patients as high risk for becoming refractory to conventional management of symptomatic cerebral vasospasm that results in cerebral infarction.

In contrast to findings reported by Qureshi et al. ${ }^{28}$ and Baldwin et al., ${ }^{2}$ the current study did not find a relationship between UEAV and 3-month functional outcome. DCI is the most likely path through which UEAV would impact functional outcome. The fact that only $23 \%$ of patients with UEAV developed DCI in combination with the observed difference in UEAV incidence between the current study (4.6\%) and those published previously (approximately $10 \%$ ) may contribute to explaining this discrepancy in study findings. If UEAV incidence is $10 \%$, the current study is adequately powered to detect as small as a 1.2 OR of poor outcome for patients with UEAV. However, at the observed $4.6 \%$ incidence rate, to detect an effect of UEAV on poor outcome with $90 \%$ power, an effect size of 


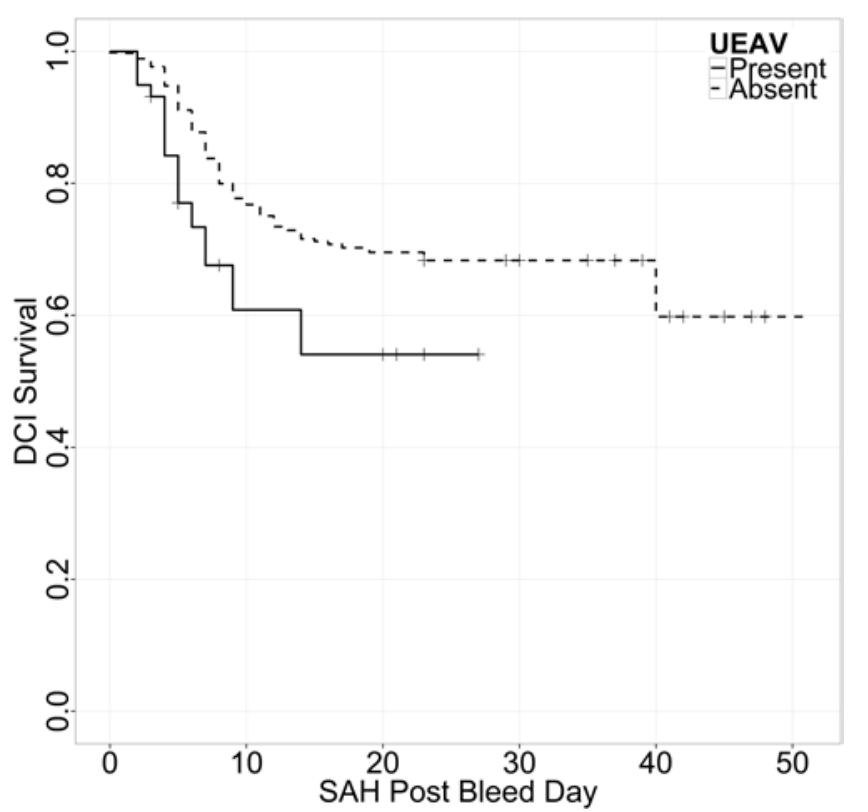

FIG. 3. A multivariable Cox regression model revealed that the presence of UEAV was significantly associated with an increased hazard of $\mathrm{DCl}$ (hazard ratio [HR] 1.7, 95\% $\mathrm{Cl} 1.1-2.7, \mathrm{p}=0.013$ ) after controlling for known predictors including younger age $(\mathrm{HR} 1.1,95 \% \mathrm{Cl} 0.9-1.4$, $\mathrm{p}=0.3$ ), poor clinical grade on admission (HR 1.4, 95\% Cl 1.1-1.8, $p=$ 0.004), thick SAH blood on admission CT scan (HR 1.2, 95\% Cl 0.9-1.6, $p=0.11)$, anterior aneurysm location (HR 1.2, 95\% Cl 1.0-1.6, $p=$ 0.037 ), and admission mean arterial pressure (MAP) greater than 112 $\mathrm{mm} \mathrm{Hg}(\mathrm{HR} 1.7,95 \% \mathrm{Cl} 1.1-2.7, \mathrm{p}=0.013)$.

1.6 is required. The Tirilazad studies ${ }^{2,28}$ observed an OR effect size of 1.5. The previous studies also reflect trends in clinical management of SAH that were popular almost 20 years ago. It is possible that current clinical practices have improved patient care and eliminated or reduced the negative impact of UEAV to such a level that a much larger cohort of patients is required to detect its negative effect on outcome. It should also be considered possible that there is a subpopulation of patients with SAH enrolled in the Tirilazad trials who are more likely to experience UEAV and have it affect their outcome. These remain unresolved issues that should be considered in future studies.

Several limitations to this study deserve mention. In contrast to the Tirilazad studies, this is a single-center study that needs to be replicated to determine how generalizable the current findings are. Although the determination of angiographic vasospasm was blind to outcome and conducted prospectively, the exact degree of cerebral vasospasm present was not available in all patients. Not all patients had DSA performed and the timing of studies was variable across patients. It remains unknown whether these are clinically relevant considerations regarding the relationship of UEAV to DCI risk. Cerebral infarction was determined primarily through CT scan, and it is possible that additional infarction or early evidence of DCI would be detected using MRI if it was safe and logistically feasible to obtain such scanning routinely. Future studies should consider the feasibility of standardizing these factors.

\section{Conclusions}

The incidence of UEAV may be as low as $4 \%-5 \%$ of patients with aSAH and is associated with a 2-fold increase in the risk of DCI and cerebral infarctions. Sentinel headaches were associated with an increased risk of developing UEAV but does not appear to confound or mediate the observed effect of UEAV on DCI and cerebral infarctions. Clinicians should monitor UEAV patients vigilantly for signs of DCI early in their course and recognize that these patients are at high risk to be refractory to cerebral vasospasm treatment. Further research is needed to determine the clinical significance of UEAV on functional outcome.

\section{References}

1. Akins PT, Levy KJ, Cross AH, Goldberg MP, Schieber MH: Postpartum cerebral vasospasm treated with hypervolemic therapy. Am J Obstet Gynecol 175:1386-1388, 1996

2. Baldwin ME, Macdonald RL, Huo D, Novakovic RL, Goldenberg FD, Frank JI, et al: Early vasospasm on admission angiography in patients with aneurysmal subarachnoid hemorrhage is a predictor for in-hospital complications and poor outcome. Stroke 35:2506-2511, 2004 (Erratum in Stroke 36:175, 2005)

3. Broderick JP, Brott TG, Duldner JE, Tomsick T, Leach A: Initial and recurrent bleeding are the major causes of death following subarachnoid hemorrhage. Stroke 25:1342-1347, 1994

4. Chhor V, Le Manach Y, Clarençon F, Nouet A, Daban JL, Abdennour L, et al: Admission risk factors for cerebral vasospasm in ruptured brain arteriovenous malformations: an observational study. Crit Care 15:R190, 2011

5. Claassen J, Bernardini GL, Kreiter K, Bates J, Du YE, Copeland D, et al: Effect of cisternal and ventricular blood on risk of delayed cerebral ischemia after subarachnoid hemorrhage: the Fisher scale revisited. Stroke 32:2012-2020, 2001

6. Connolly ES Jr, Rabinstein AA, Carhuapoma JR, Derdeyn CP, Dion J, Higashida RT, et al: Guidelines for the management of aneurysmal subarachnoid hemorrhage: a guideline for healthcare professionals from the American Heart Association/American Stroke Association. Stroke 43:1711-1737, 2012

7. Cruickshank JM, Neil-Dwyer G, Lane J: The effect of oral propranolol upon the ECG changes occurring in subarachnoid haemorrhage. Cardiovasc Res 9:236-245, 1975

8. de Haan R, Limburg M, Bossuyt P, van der Meulen J, Aaronson N: The clinical meaning of Rankin 'handicap' grades after stroke. Stroke 26:2027-2030, 1995

9. Diringer MN, Bleck TP, Claude Hemphill J III, Menon D, Shutter L, Vespa P, et al: Critical care management of patients following aneurysmal subarachnoid hemorrhage: recommendations from the Neurocritical Care Society's Multidisciplinary Consensus Conference. Neurocrit Care 15:211-240, 2011

10. Dublin AB, French BN: Cerebral aneurysmal rupture during angiography with confirmation by computed tomography: a review of intra-angiographic aneurysmal rupture. Surg Neurol 13:19-26, 1980

11. Frontera JA, Fernandez A, Schmidt JM, Claassen J, Wartenberg KE, Badjatia N, et al: Defining vasospasm after subarachnoid hemorrhage: what is the most clinically relevant definition? Stroke 40:1963-1968, 2009

12. Hackett ML, Anderson CS: Health outcomes 1 year after subarachnoid hemorrhage: An international population-based study. Neurology 55:658-662, 2000

13. Hauerberg J, Andersen BB, Eskesen V, Rosenørn J, Schmidt $\mathrm{K}$ : Importance of the recognition of a warning leak as a sign 
of a ruptured intracranial aneurysm. Acta Neurol Scand 83:61-64, 1991

14. Hop JW, Rinkel GJ, Algra A, van Gijn J: Case-fatality rates and functional outcome after subarachnoid hemorrhage: a systematic review. Stroke 28:660-664, 1997

15. Hütter BO, Kreitschmann-Andermahr I, Mayfrank L, Rohde V, Spetzger U, Gilsbach JM: Functional outcome after aneurysmal subarachnoid hemorrhage. Acta Neurochir Suppl 72:157-174, 1999

16. Jakobsson KE, Säveland H, Hillman J, Edner G, Zygmunt S, Brandt L, et al: Warning leak and management outcome in aneurysmal subarachnoid hemorrhage. J Neurosurg 85:995999, 1996

17. Jun P, Ko NU, English JD, Dowd CF, Halbach VV, Higashida RT, et al: Endovascular treatment of medically refractory cerebral vasospasm following aneurysmal subarachnoid hemorrhage. AJNR Am J Neuroradiol 31:1911-1916, 2010

18. Kassell NF, Sasaki T, Colohan AR, Nazar G: Cerebral vasospasm following aneurysmal subarachnoid hemorrhage. Stroke 16:562-572, 1985

19. Kassell NF, Torner JC, Haley EC Jr, Jane JA, Adams HP, Kongable GL: The International Cooperative Study on the Timing of Aneurysm Surgery. Part 1: Overall management results. J Neurosurg 73:18-36, 1990

20. Koenig GH, Marshall WH Jr, Poole GJ, Kramer RA: Rupture of intracranial aneurysms during cerebral angiography: report of ten cases and review of the literature. Neurosurgery 5:314-324, 1979

21. Komotar RJ, Schmidt JM, Starke RM, Claassen J, Wartenberg KE, Lee K, et al: Resuscitation and critical care of poorgrade subarachnoid hemorrhage. Neurosurgery 64:397-411, 2009

22. Kothbauer K, Schroth G, Seiler RW, Do DD: Severe symptomatic vasospasm after rupture of an arteriovenous malformation. AJNR Am J Neuroradiol 16:1073-1075, 1995

23. Li T, Hutfless S, Dickersin K, Scharfstein D, Neaton J, Hogan $\mathrm{H}$, et al: Minimal Standards in the Prevention and Handling of Missing Data in Observational and Experimental Patient Centered Outcomes Research. Washington, DC: Patient-Centered Outcomes Research Institute, 2012

24. Macdonald RL: Delayed neurological deterioration after subarachnoid haemorrhage. Nat Rev Neurol 10:44-58, 2014

25. Naidech AM, Kreiter KT, Janjua N, Ostapkovich ND, Parra A, Commichau C, et al: Cardiac troponin elevation, cardiovascular morbidity, and outcome after subarachnoid hemorrhage. Circulation 112:2851-2856, 2005

26. Naredi S, Lambert G, Edén E, Zäll S, Runnerstam M, Rydenhag B, et al: Increased sympathetic nervous activity in patients with nontraumatic subarachnoid hemorrhage. Stroke 31:901-906, 2000

27. Ogilvy CS, Carter BS: A proposed comprehensive grading system to predict outcome for surgical management of intracranial aneurysms. Neurosurgery 42:959-970, 1998

28. Qureshi AI, Sung GY, Suri MA, Straw RN, Guterman LR,
Hopkins LN: Prognostic value and determinants of ultraearly angiographic vasospasm after aneurysmal subarachnoid hemorrhage. Neurosurgery 44:967-974, 1999

29. Ringer AJ, Qureshi AI, Kim SH, Fessler RD, Guterman LR, Hopkins LN: Angioplasty for cerebral vasospasm from eclampsia. Surg Neurol 56:373-379, 2001

30. Rubin DB: Multiple Imputation for Nonresponse in Surveys. New York: Wiley, 1994

31. Su YS, Gelman A, Hill J, Yajima M: Multiple imputation with diagnostics (mi) in R: Opening windows into the black box. J Stat Softw 45:1-31, 2011

32. Taneda M, Otsuki H, Kumura E, Sakaguchi T: Angiographic demonstration of acute phase of intracranial arterial spasm following aneurysm rupture. Case report. J Neurosurg 73:958-961, 1990

33. van Gijn J, Kerr RS, Rinkel GJ: Subarachnoid haemorrhage. Lancet 369:306-318, 2007

34. Vergouwen MD, Ilodigwe D, Macdonald RL: Cerebral infarction after subarachnoid hemorrhage contributes to poor outcome by vasospasm-dependent and -independent effects. Stroke 42:924-929, 2011

35. Wilkins RH: Aneurysm rupture during angiography: does acute vasospasm occur? Surg Neurol 5:299-303, 1976

\section{Disclosures}

Dr. Witsch received a Deutsche Forschungsgemeinschaft Research Fellowship to conduct this study. Dr. Mayer has served as a consultant to Actelion Pharmaceuticals and Edge Therapeutics. Dr. Claassen has served as a consultant to Sage Therapeutics and Actelion Pharmaceuticals.

\section{Author Contributions}

Conception and design: all authors. Acquisition of data: all authors. Analysis and interpretation of data: all authors. Drafting the article: Schmidt, Al-Mufti, Roh, Lahiri, E Meyers, Witsch, Dangayach, Agarwal, Park, Connolly, Claassen. Critically revising the article: all authors. Reviewed submitted version of manuscript: all authors. Approved the final version of the manuscript on behalf of all authors: Schmidt. Statistical analysis: Schmidt, Al-Mufti, Roh, E Meyers, Witsch, Frey, Falo, Mayer, Agarwal, Park, PM Meyers, Connolly, Claassen. Administrative/techni$\mathrm{cal} /$ material support: Schmidt, Al-Mufti, Roh, Lahiri, E Meyers, Witsch, Frey, Dangayach, Falo, Mayer, Agarwal, Park, PM Meyers, Connolly, Claassen. Study supervision: Schmidt, Al-Mufti, Roh, Lahiri, Witsch, Mayer, Agarwal, Park, PM Meyers, Connolly, Claassen.

\section{Correspondence}

J. Michael Schmidt, Columbia University Medical Center, 177 Fort Washington Ave., Milstein Hospital, Ste. 8-300, New York, NY 10032. email: jmichael.schmidt@columbia.edu. 